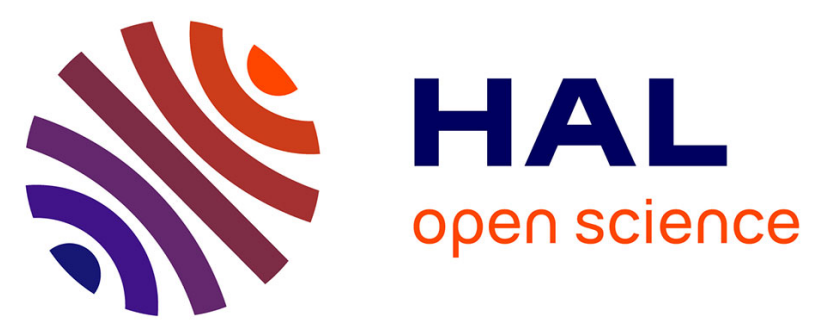

\title{
Progress in neutron techniques: towards improved polymer electrolyte membranes for energy devices
}

Fabrizia Foglia, Sandrine Lyonnard, Victoria García Sakai, Quentin Berrod, Jean-Marc Zanotti, Gérard Gebel, Adam J Clancy, Paul F Mcmillan

\section{- To cite this version:}

Fabrizia Foglia, Sandrine Lyonnard, Victoria García Sakai, Quentin Berrod, Jean-Marc Zanotti, et al.. Progress in neutron techniques: towards improved polymer electrolyte membranes for energy devices. Journal of Physics: Condensed Matter, 2021, 33, 10.1088/1361-648X/abfc10 . hal-03357975

\section{HAL Id: hal-03357975 \\ https://hal.science/hal-03357975}

Submitted on 29 Sep 2021

HAL is a multi-disciplinary open access archive for the deposit and dissemination of scientific research documents, whether they are published or not. The documents may come from teaching and research institutions in France or abroad, or from public or private research centers.
L'archive ouverte pluridisciplinaire HAL, est destinée au dépôt et à la diffusion de documents scientifiques de niveau recherche, publiés ou non, émanant des établissements d'enseignement et de recherche français ou étrangers, des laboratoires publics ou privés. 
PAPER • OPEN ACCESS

Progress in neutron techniques: towards improved polymer electrolyte membranes for energy devices

To cite this article: Fabrizia Foglia et al 2021 J. Phys.: Condens. Matter 33264005

View the article online for updates and enhancements.

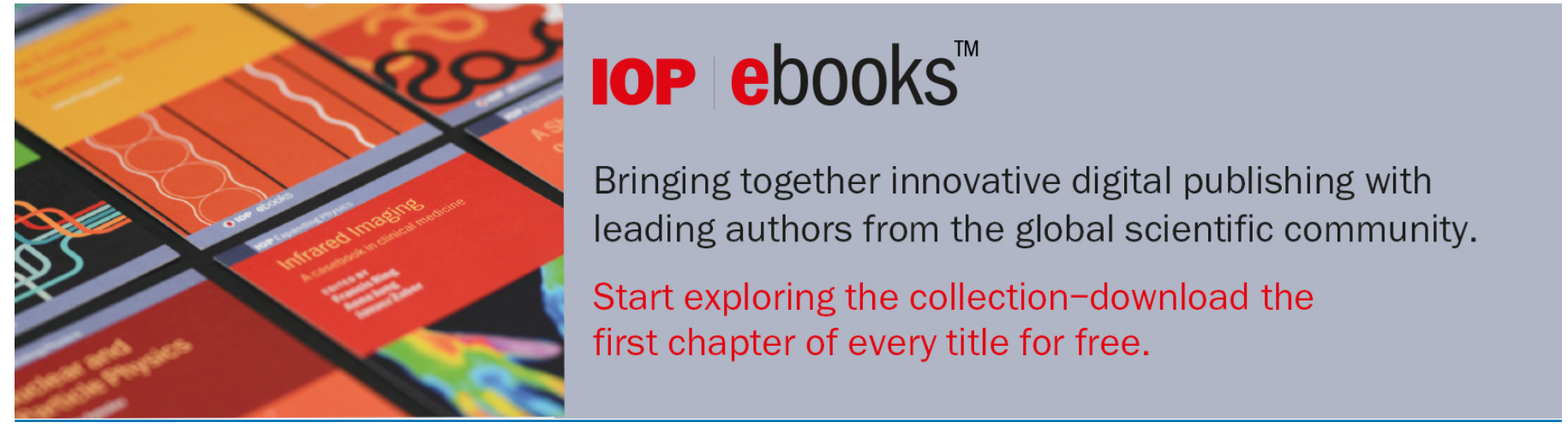

This content was downloaded from IP address 132.166.183.104 on 29/09/2021 at 09:12 


\title{
Progress in neutron techniques: towards improved polymer electrolyte membranes for energy devices
}

\author{
Fabrizia Foglia $^{1, *} \mathbb{0}$, Sandrine Lyonnard², Victoria García Sakai ${ }^{3}$, \\ Quentin Berrod ${ }^{2}$, Jean-Marc Zanotti ${ }^{4}$, Gérard Gebel ${ }^{5}$, Adam J Clancy ${ }^{1}$ (] \\ and Paul F McMillan ${ }^{1, *}$ \\ 1 Department of Chemistry, Christopher Ingold Laboratory, University College London, 20 Gordon St., \\ London WC1H 0AJ, United Kingdom \\ 2 University Grenoble Alpes, CNRS, CEA, IRIG-SyMMES, 38000 Grenoble, France \\ ${ }^{3}$ ISIS Neutron and Muon Source, Rutherford Appleton Laboratory, Harwell Science and Innovation \\ Campus, Chilton OX11 0QX, United Kingdom \\ ${ }^{4}$ Laboratoire Léon Brillouin (CEA-CNRS), Université Paris-Saclay, CEA Saclay, 91191 Gif-sur-Yvette \\ Cedex, France \\ 5 University Grenoble Alpes, CEA LITEN, 38000 Grenoble, France \\ E-mail: f.foglia@ucl.ac.uk and p.f.mcmillan@ucl.ac.uk
}

Received 30 January 2021, revised 2 April 2021

Accepted for publication 27 April 2021

Published 28 May 2021

\begin{abstract}
Design and implementation of advanced membrane formulations for selective transport of ions and molecular species are critical for creating the next generations of fuel cells and separation devices. It is necessary to understand the detailed transport mechanisms over time- and length-scales relevant to the device operation, both in laboratory models and in working systems under realistic operational conditions. Neutron scattering techniques including quasi-elastic neutron scattering, reflectivity and imaging are implemented at beamline stations at reactor and spallation source facilities worldwide. With the advent of new and improved instrument design, detector methodology, source characteristics and data analysis protocols, these neutron scattering techniques are emerging as a primary tool for research to design, evaluate and implement advanced membrane technologies for fuel cell and separation devices. Here we describe these techniques and their development and implementation at the ILL reactor source (Institut Laue-Langevin, Grenoble, France) and ISIS Neutron and Muon Spallation source (Harwell Science and Technology Campus, UK) as examples. We also mention similar developments under way at other facilities worldwide, and describe approaches such as combining optical with neutron Raman scattering and x-ray absorption with neutron imaging and tomography, and carrying out such experiments in specialised fuel cells designed to mimic as closely possible actual operando conditions. These experiments and research projects will play a key role in enabling and testing new membrane formulations for efficient and sustainable energy production/conversion and separations technologies.
\end{abstract}

* Authors to whom any correspondence should be addressed. 
Keywords: neutron scattering, QENS, reflectivity, membranes, fuel cell, separation

(Some figures may appear in colour only in the online journal)

\section{Introduction}

With the goal to reduce carbon emissions to net zero by 2050 substantial research is being directed at developing novel materials and hierarchical structures for energy harvesting, storage and conversion devices. Key to many of these applications is the development and optimization of ion-selective membranes that provide a key component necessary for the operation of fuel cells, electrolyzers and redox flow batteries, as well as in nanofiltration for water purification and separation applications [1-4]. Critical issues that are currently being investigated address improvements in durability and performance efficiency combined with lowered production costs [5, $6]$. Research to develop and model the chemistry and improve the performance of novel as well as current membrane formulations is under way in laboratories worldwide [6-10]. Neutron scattering (NS) and imaging techniques designed to probe the structure and dynamics of bulk and thin film materials are playing an increasing role in studies to understand, control and develop critical issues of water uptake and management related to polymer structure, selective transport of ions and molecular species through the membrane, and the coupling between these dynamic processes.

While various new chemistries are under development, poly(perfluorosulfonic acid)-based Nafion ${ }^{\circledR}$ membranes developed as proton-conducting membranes still dominate the market and are used as state-of-the-art reference materials, despite suffering from poor selectivity due to swelling in water. The hydration-dependent nanostructure of these materials has been extensively studied by small angle X-ray and neutron scattering (SAXS, SANS) [11, 12] complemented by quasi-elastic neutron scattering (QENS), to investigate both water and ion dynamics [13-20]. The studies are now being extended to in situ investigations carried out under typical operando conditions within working fuel cells and ion-selective separation devices [21-27]. Ion transport within these polymers depends on the formation of interconnected channels, that depends upon the chemical and physical characteristics of the polymer and the degree of hydration [28-30]. Significant challenges include achieving precise control over pore architecture and size distribution [4, 7, $8,31-33]$ to obtain next generations of highly performing membranes, for operations over a wide temperature range while optimizing lifetime, that permit selective transport of either cationic $\left(\mathrm{H}^{+}\right)$or anionic $\left(\mathrm{OH}^{-}\right)$charge-carrying species to enable implementation of either proton- or anion-exchange fuel cells and other devices.

To address these targets, the main strategies being implemented in academic and industry research laboratories worldwide are based on the development of: (i) new synthetic membranes, where careful design of chemical and physical properties is being used to tune channel size and distribution [34-36]; as well as (ii) formation of composite membranes, where the incorporation of fillers (e.g. silica, clay, zeolites, etc) into the Nafion membrane serves to increase the thermal, chemical and mechanical resistance while playing a role in managing water uptake, membrane swelling and ion transport [37-40]. Recent research is directed at introducing low-dimensional nanoporous materials including graphene oxide or graphitic carbon nitride into the polymeric matrix [4, 41-43] (figure 1), or by using metal organic framework membranes [44, 45].

\section{Neutron scattering as a tool}

To evaluate the performance of existing and new membrane formulations, it is necessary to understand not only their polymeric and hierarchical structures across molecular to mesoscopic length scales, but also to study their water uptake, ion conductivity and polymer dynamics over picosecond to nanosecond timescales. These goals are achieved using NS techniques that exist or are under development at various facilities worldwide (table 1). The local dynamics in relation to the molecular structure are examined by QENS, while throughdepth profiling of the chemical composition and structure of membrane materials is achieved by neutron reflectivity (NR) [46]. Operando studies using these techniques as well as smalland wide-angle neutron scattering (SANS and WANS) are beginning to be implemented under conditions relevant to the functioning of actual fuel cells [21, 24, 25].

Unveiling structural and dynamical properties, as well as identifying their interplay in polymeric systems is a great challenge, which becomes even more difficult when increasing the complexity of the system (e.g. intricate monomeric units, polymer blends, nanocomposites, etc). One possible strategy is to combine NS with computer simulations (i.e. ab initio methods, fully atomistic molecular dynamics - MD — simulations, Monte Carlo methods, etc). The data provided by NS are complemented by computational studies, where experimental parameters are used to feedback into model inputs, providing an effective methodology to understand the formation, stability, and properties of membrane materials, as well as guiding the formulation of advanced designs for specific applications [17, 43, 47-54].

Unlike $\mathrm{x}$-ray beams that are commonly used for molecular characterisation, neutrons do not typically cause radiation damage to the samples under investigation, and are ideal to examine soft matter systems including fuel cell membranes. They are highly sensitive to the structure and dynamics of hydrogen-containing materials, and furthermore take 

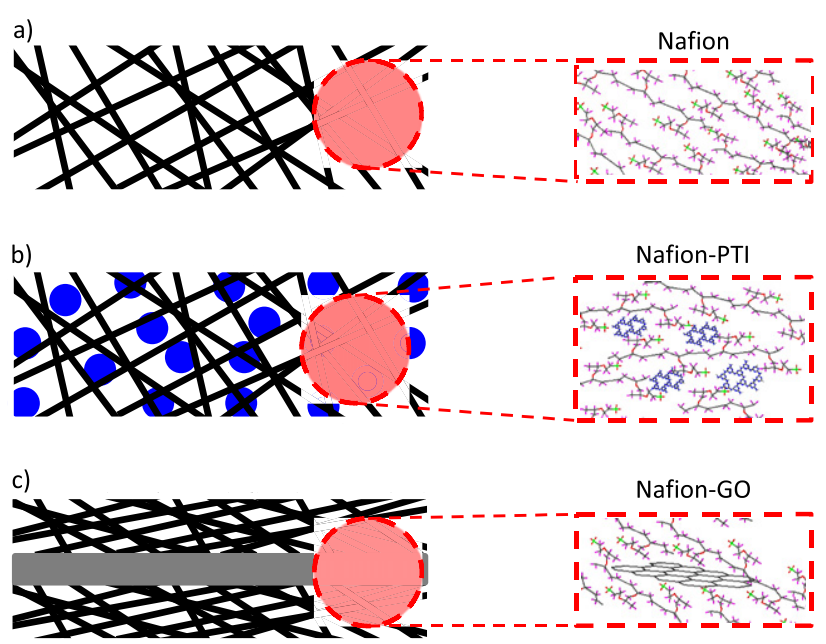

Figure 1. Schematic illustration of Nafion (a) vs Nafion composite (b) and (c) membranes. In panel (b) is represented a nanocomposite membrane where 2D nanomaterial (carbon nitride with a PTI structure) is co-deposited with Nafion. In panel (c) is represented a nanocomposite membrane where $2 \mathrm{D}$ nanomaterial $(\mathrm{GO})$ is deposited within Nafion layers.

advantage of isotopic contrast experiments to specifically highlight and disentangle processes involving different spatial regions and dynamical behaviours, that are strongly coupled together in complex multicomponent materials. Moreover, because they allow ready penetration on the order of several $\mathrm{cm}$ through metallic or ceramic containers and reaction vessels, it is possible to monitor and image time-dependent structure and dynamic processes, both in situ and under operando conditions relevant to membrane functionality [55-57]. Achieving such fundamental understanding is critical to guide the passage from laboratory experimentation to bulk material formulation with hierarchical structure designation, leading to up-scaled production of commercially relevant products.

Neutrons for scattering techniques as a tool for materials research are produced in large facilities by either fission or spallation. In research reactors such as the ILL in France, a high continuous flux of neutrons is produced by fission of heavy nuclei, yielding around one neutron per fission, with an average flux $10^{15} \mathrm{n} \mathrm{cm}^{-2} \mathrm{~s}^{-1}$ (figure 2) [58]. Reactors (i) enable resolutions that can be more easily tailored to experimental requirements, (ii) achieve higher flux that allows a unique view on large objects and slow dynamics, (iii) enable easier neutron polarization and (iv) use of a narrow wavelength band of neutrons. However, fission sources have high energy deposition per useful neutron $(\sim 180 \mathrm{MeV})$.

On the other hand a pulsed source of neutrons is produced by bombarding a heavy element target with high-energy particles, typically protons. This kind of source is typically, described according to the nature of the proton accelerator: pseudo-continuous (e.g. SINQ at PSI), short-pulse (e.g. ISIS, SNS, and J-PARC), or long-pulse (e.g. ESS and SNS 2nd target station) sources. The spallation process typically produces around 30 neutrons per proton $(\sim 15$ in the specific case of ISIS), with an average flux of $10^{13} \mathrm{n} \mathrm{cm}^{-2} \mathrm{~s}^{-1}$ despite a high peak flux ( $\sim 10^{15} \mathrm{n} \mathrm{cm}^{-2} \mathrm{~s}^{-1}$; figure 2) [58]. Spallation sources benefit from (i) 'low' energy deposited per useful neutron of

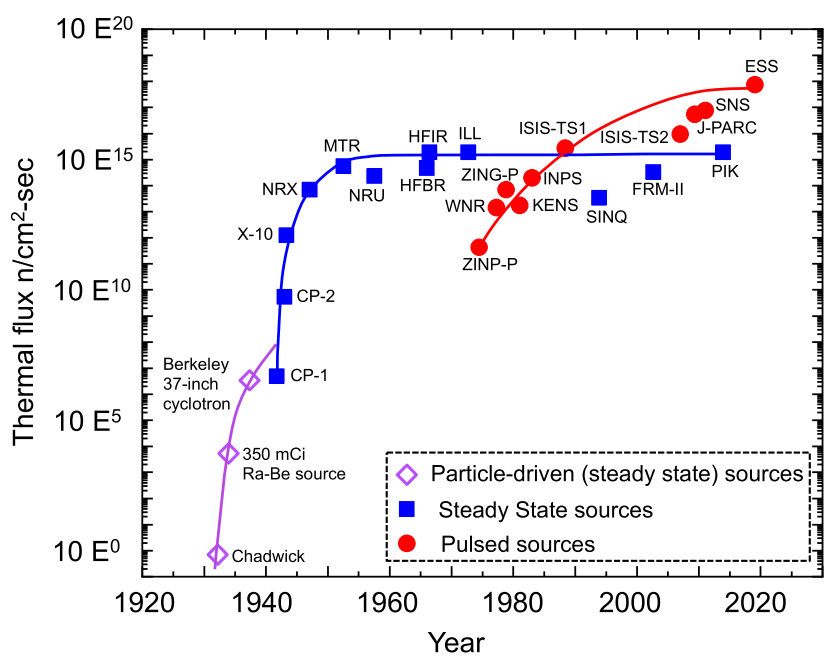

Figure 2. Thermal flux achievable at various neutron facilities. Adapted from NS, Skold and Price: eds. Academic Press, 1986 [58] where facility acronyms are defined (see also legend to table 1). Reprinted from [58], Copyright (1986), with permission from Elsevier.

$\sim 30 \mathrm{MeV}(\sim 6 \times$ more neutron per unit heat compared to reactor source), (ii) a time structure which is advantageous for some experiments, (iii) a broad wavelength band from each pulse, and (iv) lowered political implications compared with nuclear reactor sources. However, the reduced flux at spallation sources leads to longer acquisition times while the useful time structure is not implemented for all instruments.

The neutron flux in both types of sources needs to be thermally moderated to sub- $\AA$ to tens of $\AA$ wavelengths to be useful in NS experiments. So-called 'cold' neutrons, with wavelengths in the range of 4 to $30 \AA$ (i.e., energies from $\mu \mathrm{eV}$ to several $\mathrm{meV}$ ) permit investigations of structural correlations from 0.1 to a few $100 \mathrm{~nm}$ in length and beyond, in combination with studies of molecular motions on the pico- to nano-second time regime.

Neutron sources are constantly in development [59, 60] to provide innovative and more powerful neutron instrumentation that is being applied to advanced membrane research. One such instrument is the LET spectrometer [61] at the ISIS Facility, UK, whose unique features allow accessing an exceptionally wide dynamic range (by around three orders of magnitude), distinguishing between magnetic and spin incoherent excitations [62] and to completely map out reciprocal space throughout the Brillouin zone [63]. Other features of LET are: (i) the combination of time-of-flight spectroscopy (TOF) and longitudinal polarization analysis [64], that opens up the possibility of simultaneously separating cross-section components over wide regions in $(Q, \omega)$ space; and (ii) the implementation of the repetition rate multiplication method [65]. This method uses a set of monochromatic wavelengths derived from each source pulse to permit in-depth studies of samples with complex inelastic behaviour. In practical terms this allows access to concurrent measurements at different energy resolution, and thus to studies of both slow dynamics and fast local/diffusive motions. Other upgrade projects include the addition of a Si111 analyser bank [66] and a guide upgrade [67] on the 
Table 1. Example beamlines suitable for NS techniques: Oak Ridge National Laboratory Spallation Neutron Source (ORNL), USA;

National Institute of Standards and Technology Center (NIST) for Neutron Research, USA; Paul Scherrer Institute (SINQ), Switzerland; Australian Nuclear Science and Technology Organisation (ANSTO); Japan Proton Accelerator Research Complex (J-PARC), Materials Life Science, Japan; (FRM-II) Research Neutron Source Heinz Maier-Leibnitz Forschungsreaktor München II.

\begin{tabular}{llll}
\hline & \multicolumn{1}{c}{ ISIS } & \multicolumn{1}{c}{ ILL } & \multicolumn{1}{c}{ Other worldwide } \\
\hline QENS & LET, Iris, Osiris & IN16B, SHARP, IN5, PANTHER & $\begin{array}{l}\text { BASIS \& CNCS (ORNL); DCS \& HFBS (NIST); } \\
\text { Emu (ANSTO), BL12-HRC, DNA \& AMATERAS } \\
\text { (J-PARC); TOFTOF (FRM-II) }\end{array}$ \\
NR & Offspec, Inter, Surf, Polaref & FIGARO, D17, SuperADAM & $\begin{array}{l}\text { Liqref \& MAGREF (ORNL); CANDOR (NIST); } \\
\text { AMOR \& MORPHEUS (SINQ); Platypus (ANSTO); }\end{array}$ \\
& & & NREX (FRM-II) \\
NI & IMAT & NEXT & IMAGING (ORNL); NIF (NIST); Dingo (ANSTO); \\
Ultra Small - & NIMROD, SANDALS, LoQ, & D4, D11, D16, D22, D33 & ANTARES (FRM-II) \\
$\begin{array}{l}\text { Small - } \\
\text { Wide Angle }\end{array}$ & Sans2D, Larmor, Zoom & & EQ-SANS \& USANS (ORNL); SANS-I (SINQ); \\
\hline
\end{tabular}

OSIRIS backscattering spectrometer, which will increase the dynamic range to probe processes with longer characteristic relaxations times and complement the capabilities of LET, and achieve a factor 5-6 gain in intensity important for thin film experiments. In addition to the on-going upgrades to spectrometers, ISIS has three state-of-the-art membrane-relavent reflectometers: INTER [68], POLREF [69] and OFFSPEC [70], which because of their large neutron flux are particularly adapted for collection of scattering signal over a wide range of momentum transfer $(Q)$ and intensity, useful for timeresolved kinetics studies [71]. POLREF and OFFSPEC also allow a complementary analysis of in-plane membrane and thin film structures and their structural and chemical heterogeneity, leading to more realistic models of model membranes as well as analytical devices.

The ILL reactor in France has also experienced relevant upgrades and instrumentation developments. A recent development for neutron reflectometry involves use of a prism with a curved surface, instead of traditional choppers. This upgrade involves applying refractive analysis to the incoming neutron beam over the white spectrum, and the RAINBOWS [72] instrument will increase the transmission by up to two orders of magnitude. Coupled with high spatial resolution detectors this will significantly enable advanced studies of reaction kinetics and materials and devices under operando conditions. This upgrade is intended to be available initially for the FIGARO reflectometer (optimized for horizontal surfaces with option of either reflection up or down) and then extended to the D17 reflectometer (vertical surfaces).

In spectroscopy, two upgrades are worth mentioning. First, a cold inelastic TOF spectrometer SHARP [73, 74] is being built at ILL as a collaborative project between Sweden and France. This instrument combines the time-focusing advantage, with four instrument resolutions ranging from 50 to $170 \mu \mathrm{eV}$, with a high detection quality leading to a large improvement in the definition and mapping of the $(Q, \omega)$ domain, essential for the detection of anisotropic signals. A key feature is the incorporation of a TOF chamber which offers the possibility for studies of samples under vacuum or in a controlled atmosphere. The capabilities of SHARP are particularly relevant for studies of materials for energy devices, as well as biology and soft condensed matter, where multiscale dynamics including interactions at interfaces and/or severe confinement are at play [75-77]. By 2023, the latest version of the spectrometer $(\mathrm{SHARP}+)$ will offer a $15 \times$ gain in the counting rate compared to the IN6 instrument previously located at this station. These improvements will be critical to follow the relaxation of membrane materials during and following electrical excitation. Also, the so-called BATS option (BATS: backscattering and TOF spectrometer) is implemented for the IN16B high-resolution backscattering instrument. This operational mode extends the energy window by over one order of magnitude $(340 \mu \mathrm{eV})$ with only slightly broadened resolution $(1.2 \mu \mathrm{eV})$, to allow studies of slow dynamics over a much wider timescale than before [78].

In addition to these developments at ISIS and ILL facilities, major efforts are being directed at developing nextgeneration very high-brilliance sources incorporating instrumentation with very fast collection times and high-sensitivity detectors for advanced materials research and other studies. The user programme at the new European Spallation Source (ESS) in Sweden is expected to begin in 2023 [79], where instruments such as C-SPEC (TOF spectrometer), VESPA (vibrational spectrometer) and FREIA (reflectometer) will offer unique characteristics combined with the high source brilliance to enable time-resolved studies of non-equilibrium phenomena and operando investigations of working devices. Other neutron facilities outside Europe also have similar cutting-edge improvement projects under way, such as the power upgrade and construction of a second target station at the Spallation Neutron Source (SNS) at Oak Ridge National Laboratory (USA) [80, 81].

All of these upgrades and instrumental innovations for advanced NS, along with the recent development of flexible and compact sources [82-84] that can be tailored around the needs of an individual instrument or specific experiment, apply particularly to materials and processes involving light atoms such as hydrogen and lithium that play a central role in energy generation and storage devices [85]. NS allows researchers to 
pinpoint precisely where such atoms occur within the structure and how they move under operando conditions [24, 55-57], that are necessary to design and optimise next-generation fuel cells and other energy devices. In this way, the NS experiments will play a key role in helping guide the transition of materials from the laboratory to functional components of operating devices, and then to commercialisation and widespread implementation. Some of the current implementations and challenges facing fuel cell technology are outlined in the next section.

\section{Fuel cell technology}

A viable alternative to combustion-based technologies is provided by fuel cells (FCs), that offer sustainable solutions for a wide range of stationary and transportation power requirements, and for applications providing electrical energy at efficiencies of up to $60 \%$. Because FCs emit only water as a primary exhaust, they represent a realistic solution to reduce carbon dioxide emissions and air pollutants.

Despite these advantages, there are still limitations to their implementation including: (i) irreversible potential losses related to Ohmic processes where activation mass transport issues remain to be resolved; (ii) their durability that is currently set at a target of around 7 and 55 months for transportation and stationary applications, respectively, but must be improved [32, 86]; (iii) their high cost when integrated into current membrane-electrode (MEA) assemblies because expensive and resource-limited transition metals such as $\mathrm{Pt}$ are incorporated in the necessary electrocatalyst formulation. This latter issue is being addressed through development of anion-exchange (AEMFC) devices that can operate efficiently using more easily resourceable metal catalysts such as $\mathrm{Ni}$ [87]. However membranes for use in these devices are still being researched as their performance must be improved for effective operation in an alkaline environment [88], as well as to survive the harsh chemical and transient mechanical stresses experienced under operating conditions $[89,90]$.

A fundamental issue for fuel cell implementation concerns the optimization and control of water management in the FC device. Water uptake by the ion-conducting membrane is usually expressed in terms of a parameter $\lambda$ [91], that expresses the number of $\mathrm{H}_{2} \mathrm{O}$ molecules per functional group involved in ion exchange processes. This critical property directly influences the ionic conductivity, and correlates with the chemical and physical structure of the polymer, as well as the operating temperature range.

Fuel cell devices developed around electrocatalytic reactions to generate $\mathrm{H}^{+}$from $\mathrm{H}_{2}$ fuel at the anode followed by transport through an ionomeric membrane to react with oxygen reduced at the cathode (proton exchange membrane or PEMFC systems) are based on the classic family of sulphonated tetrafluoroethylene fluoropolymers discovered by Walther Grot of DuPont in the 1960s, and implemented as Nafion membrane materials in all PEMFC devices since then. Despite intensive research efforts since then to improve its performance, Nafion and analogues such as Aquivion, Gore, etc

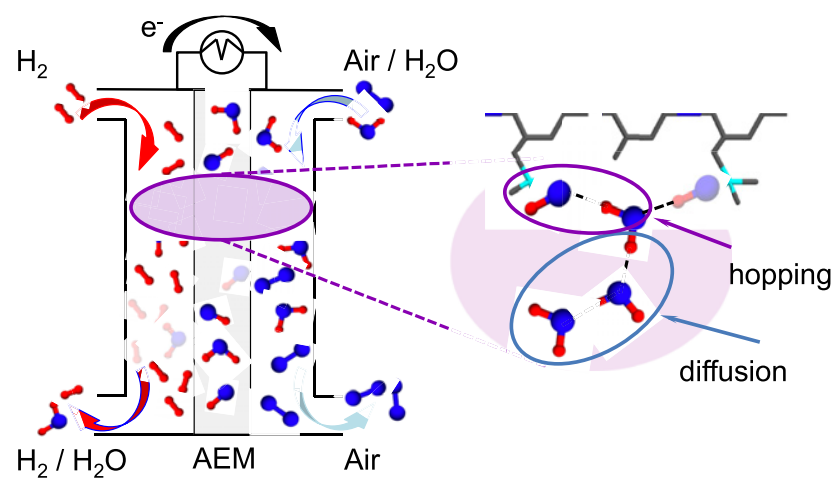

Figure 3. Schematic illustration of an alkaline fuel cell (AEMFC) and its mode of operation, including a sketch indicating the main modes of $\mathrm{OH}^{-} / \mathrm{H}_{2} \mathrm{O}$ transport.

commercialised by other companies, have continued to provide the membrane material of choice for fuel cell technology.

One of the main limitations of PEMFCs is the need to use expensive and resource-limited Pt-based electrocatalysts to enable efficient $\mathrm{O}_{2}$ cathodic reduction as well as implement $\mathrm{H}_{2}$ oxidation reactions. Alternative solutions include the development and use of fuel cells that operate under alkaline conditions (AEMFCs), that can operate using more resourceable transition metals such as $\mathrm{Ni}$ as the critical electrocatalyst material [92]. Although initial studies have been carried out using Nafion and related membrane systems, efficient implementation of AEMFCs requires formulation and development of alternative membranes adapted to operate under such highly alkaline conditions. This a topic of intense research among the international energy materials community. From research on PEM systems including detailed NS studies, it is established that ionic conductivity relates to transport of $\mathrm{H}^{+}$via Grotthus hopping in PEMFCs, and also $\mathrm{OH}^{-}$mass transport in AEMFCs, depending on the degree of hydration [14-17, $23,87-90,93$ ]. It is essential to understand the roles of spatial confinement, tortuosity, and connectivity of nanodomains in these ionic conductivity pathways. A critical role is played by water molecules, that interact strongly with the hydrophilic domain surrounding Bronsted/Lewis acidic groups attached to the polymer species, thus facilitating $\mathrm{H}^{+}$exchange with the hydrated environment. It has been shown by NS studies combined with MD simulations that $\mathrm{H}_{2} \mathrm{O}$ molecules facilitate protonic conductivity by solvating the sulfonic acid moieties, swelling the membrane, and forming a conduction pathway $[15,16,23]$.

Ion conductivity in AEMs is less well understood than $\mathrm{H}^{+}$ conductivity in PEM systems. It is currently thought to be achieved by a combination of vehicular $\mathrm{OH}^{-}$diffusion and Grotthuss hopping of protons through the H-bonded water network, with the balance between the two mechanisms determined by the water content (figure 3) [93-98]. This is achievable because of the presence of quaternary ammonium groups $\left(-\mathrm{NR}_{3}{ }^{+}\right)$distributed along the aromatic polymer backbone expressing different chemistries [99-106].

Despite improvements over the past several years, the achievable conductivity in AEMFCs is still 2 to 8 times lower than in PEMFCs at similar $\lambda$ values $[107,108]$; this is mainly 


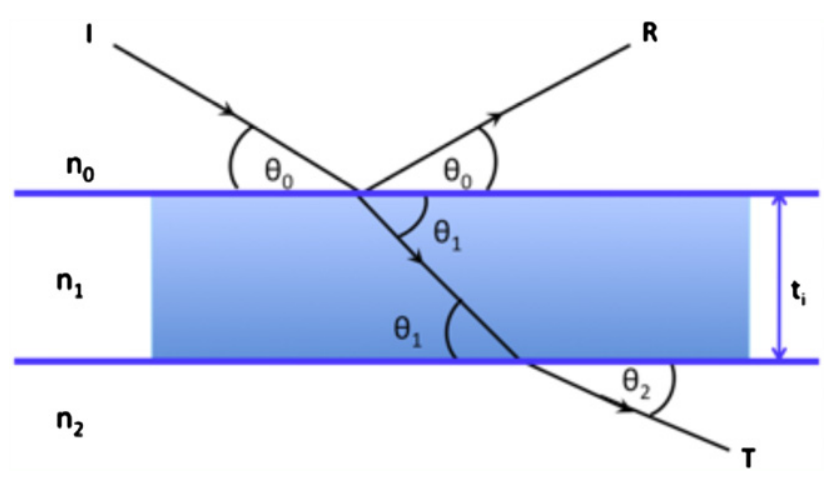

Figure 4. Schematic diagram showing the reflected $(R)$ and transmitted $(T)$ beams when an incident beam $(I)$ passes through two media with refractive indices $n_{0}$ and $n_{2}$, with an interface of thickness $t_{i}$ and refractive index $n_{1}$.

due to the higher water content required for the AEM to facilitate ionic percolation due to details of the conductivity mechanism. Increasing the $\lambda$ value causes swelling of the membrane, which results in lowered mechanical stability. It is therefore imperative to optimize the polymer molecular architecture to improve conductivity without compromising the membrane mechanical resistance at operational conditions [109-111].

\subsection{Backbone nanostructure}

One of the current strategies to improve AEM performance is to mimic and adapt design considerations from existing PEMs by including incorporation of flexible side chains [88], multicationic groups [112], a multi-block polymer backbone [113], a comb-shaped polymer architecture [104], a layered backbone [114], and radiation-grafted membranes [115].

Poly(2,6-dimethyl-1,4-phenylene oxide) (PPO) has been widely adopted as a precursor in the preparation of grafts and copolymers [103, 106]. This material has been shown to have an outstanding film forming ability as well as thermal stability, with the onset of thermal decomposition above $\sim 400{ }^{\circ} \mathrm{C}$ [116]. Although the aryl ether linkage allows enhanced rotational freedom along the backbone structure, it also leads to one of the main mechanisms of polymer degradation under high-pH conditions. The latter is accompanied by further decomposition $\left(\sim 200 \leqslant T \leqslant \sim 400{ }^{\circ} \mathrm{C}\right)$ when functional groups (e.g. quaternary ammonium cations; QA) are present [117].

Neutron reflectivity (NR), combined with X-ray reflectivity, techniques are ideal to characterise, with sub-Ångström precision, the thickness, morphology, and compositional distribution within thin film materials including FC membranes. The case of a single homogeneous thin film with thickness $t_{i}$ and refractive index $n_{1}$ is illustrated in figure 4 .

When the thin film occurs at the interface between two media with refractive indices $n_{0}$ and $n_{2}$, the reflectivity $(R)$ is given by:

$$
R=\left|\frac{n_{0} \sin \theta_{0}-n_{2} \sin \theta_{2}}{n_{0} \sin \theta_{0}+n_{2} \sin \theta_{2}}\right|^{2} .
$$

From equation (1), applying Fresnel's law allows expression of the reflectivity in terms of the momentum transfer perpendicular to the reflecting surface $\left(Q_{z}\right)$ :

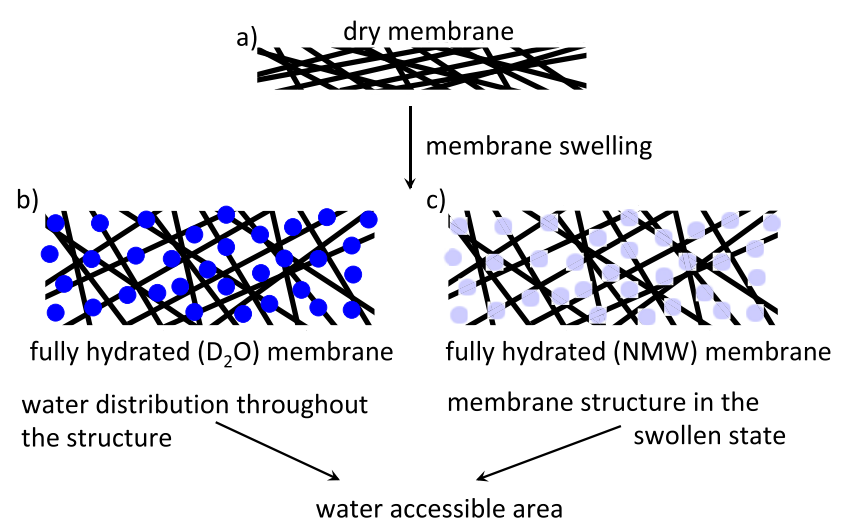

Figure 5. Cartoon showing the contrast variation technique for NR using $\mathrm{D}_{2} \mathrm{O}$ and null-matched water (NMW; mixture of $\mathrm{H}_{2} \mathrm{O}$ and $\mathrm{D}_{2} \mathrm{O}$ with $\mathrm{SLD}=0$ ).

$$
R\left(Q_{z}\right)=\left[\frac{1-\sqrt{\left(Q_{\text {crit }} / Q_{z}\right)^{2}}}{1+\sqrt{\left(Q_{\text {crit }} / Q_{z}\right)^{2}}}\right]^{2}=\frac{16 \pi^{2}}{Q_{z}^{2}}\left|\varphi^{\prime}\left(Q_{z}\right)\right|^{2}
$$

where $Q_{\text {crit }}$ relates to the critical angle at which the entire wave is reflected and $\varphi^{\prime}\left(Q_{z}\right)$ is the Fourier transform of the gradient of the scattering length density (SLD) profile normal to the interface. A NR experiment mapping the SLD in a certain volume $(V)$ allows determination of microstructure and composition of the thin film under examination:

$$
\mathrm{SLD}=\sum_{i} b_{i} / V
$$

where $b_{i}$ is the atomic scattering length.

This formalism can be extended to model the data considering a series of multiple thin layers, with SLD related by a given profile, where the intrinsic interfacial width between layers (i.e., roughness) sets a finite resolution for detecting minute composition (or density) differences at the film interfaces. This information is critical to understanding chemical composition as well as the solvent distribution within a medium. Furthermore, because NS is highly sensitive to isotopic composition especially for H/D incorporated within the sample, it is possible to highlight water uptake processes by carefully choosing the chemical composition of the hydrating medium. This leads to evaluation of: (i) membrane nanostructure and void composition (by choosing an $\mathrm{H}_{2} \mathrm{O} / \mathrm{D}_{2} \mathrm{O}$ mixture having SLD equivalent to zero; i.e. $92 \% \mathrm{H}_{2} \mathrm{O}, 8 \% \mathrm{D}_{2} \mathrm{O}$ ), or (ii) solvent mass and its distribution (e.g. by using pure $\mathrm{D}_{2} \mathrm{O}$ ) throughout the film (figure 5).

Furthermore, the variation of SLD allows evaluation of changes in density [46] as $V$ in equation (3) is defined as the product of film thickness $\left(t_{i}\right)$ and the illuminated footprint ( $A$; which remains constant during the experiment). It is then possible to calculate how the volume fraction of the starting component (e.g. dry membrane) changes during hydration, allowing mapping of membrane porosity. Most advanced reflectometers permit simultaneous acquisition of specular (i.e., profile normal to the surface; $R\left(Q_{z}\right)$ ) and off-specular (inplane correlation lengths) NR data providing access to sub- $\mu \mathrm{m}$ and $\mu \mathrm{m}$ length scales in the same experiment. 


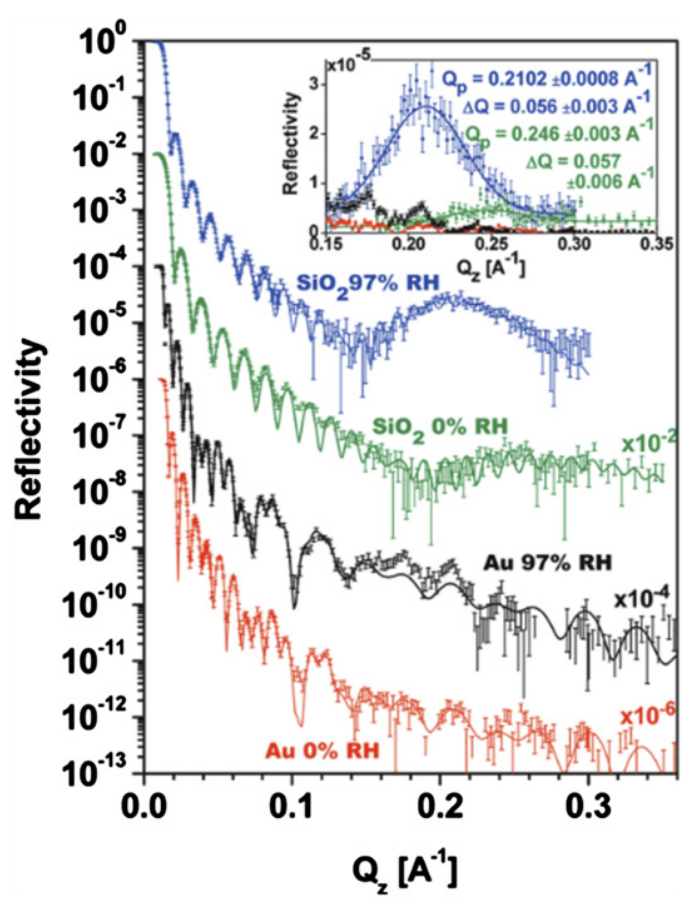

Figure 6. Specular NR data and fits of Nafion on $\mathrm{SiO}_{2}$ and $\mathrm{Au}$ in 0/97\% relative humidity measuring structural changes with substrate-impacted water swelling. Reprinted with permission from [123]. Copyright (2009) American Chemical Society.

Present limitations to the use of NR to characterise AEM membranes are primarily related to the membrane thickness, that typically exceeds the $\mu \mathrm{m}$ size range). Research is now underway to reduce the film thickness for study by approximately one order of magnitude [31, 108, 118]. This has already been demonstrated for PEMs, where NR has been used to monitor structural composition and solvent distribution under a wide range of physical conditions [119-122].

As an example of this application, when deposited on $\mathrm{SiO}_{2}$ surface, Nafion assumes a multi-lamellar form composed of alternating water-rich and Nafion-rich layers. These layers are identified by a defined peak at around $Q=0.2 \AA^{-1}$ in fully hydrated conditions, which almost disappears in dry conditions [120, 123]. When deposited on metal surfaces (e.g. Pt or $\mathrm{Au})$ the Nafion structure appears as a single water-rich layer (figure 6) [120, 123, 124].

NR data indicate that when deposited on oxide-free Pt surface, partially hydrated Nafion exhibits a tendency to push its hydrophobic component toward the Pt surface. In contrast, in the presence of an oxide layer (e.g. PtO), long-range restructuring is observed [125]. This reorganisation could be responsible for the different charge-transfer behaviour during oxygen reduction [125].

Recently, similar experiments have been extended to MEA assemblies and for binders in catalyst layers in AEM fuel cells $[126,127]$. The results will be crucial to understand the metal/binder interfaces and therefore help design and improve catalysts with non-precious metals. Kimura et al carried out series of NR experiments for a new polymer membrane chemistry (hexafluoroisopropylidene with pendant hexyltrimethylammonium; BAF-QAFs), which exhibits high $\mathrm{OH}^{-}$conductivity $\left(\sim 130 \mathrm{mS} \mathrm{cm}{ }^{-1}\right.$ at $\left.80{ }^{\circ} \mathrm{C}\right)$ and exceptional stability [126]. Their NR profiles indicate the presence of three-layered membranes with different hydration levels in $\mathrm{SiO}_{2}$ vs $\mathrm{Pt}$ deposited films. They found that the chemistry of the substrate affects the entire thin film, indicating different polymer conformations. Furthermore, they could correlate the rapid degradation of ionomers in the catalyst layer to the hydrophobicity of the Pt-attached layer [126].

NR studies can also inform the study of other energy-related materials systems and devices. This is the case for PS:PCBM (6,6-phenyl- $\mathrm{C}_{61}$-butyric acid methyl ester-polystyrene) thin films where NR provided essential new insight into the stability of these organic solar cell materials under operating conditions of light exposure and temperature [128]. Another example is provided by the operando NR measurements of the bulk c-Si electrode where $\mathrm{Li}^{+}$transport, distribution, and concentration were monitored inside the working electrode [129]. Off-specular NR measurements can give unique insights into the micro-morphology of the active (top) layer, which is intrinsically connected to device efficiency [130, 131].

At present, most NR experiments are performed in situ under laboratory controlled conditions, on model materials and samples. It is possible to monitor structure variations at different levels of relative humidity $(\mathrm{RH})$ using a humidity chamber with either vertical or horizontal geometry $[46,126]$ with temperature control up to around $100{ }^{\circ} \mathrm{C}$. For studies at higher temperatures up to around $150{ }^{\circ} \mathrm{C}$, modified vacuum chamber cells can be implemented using quartz glass windows. Such a high temperature setup was used to follow in situ annealing of polymer-fullerene mixtures to reveal the molecular mobility of the fullerenes [132].

Similar experimental arrangements will enable studies of structure and dynamics in new PEMs designed to operate at intermediate temperature (100-120 ${ }^{\circ} \mathrm{C}$; IT-PEM). These fuel cells are of particular interest because of their superior heat/water management, $\mathrm{CO}$ tolerance, and electrode reaction kinetics [133-135]. Although improved FC performances are usually recorded at high $\mathrm{RH}$, in the case of IT-PEM operation use of lower RH is desirable because of the higher saturated vapour pressure at $120{ }^{\circ} \mathrm{C}$. Accessing and controlling these conditions is crucial, as functioning at reduced humidity levels will minimise problems associated with water management (e.g. flooding), while being effective in resisting damage caused by fuel impurities [135]. Under lowRH conditions, changes in membrane properties (porosity, hydrophobicity, thickness) necessitate careful characterisation of the structure under operando conditions [136] in order to minimize Ohmic drop while managing the water content for optimal performance. Improvements in reflectivity instruments (e.g., RAINBOWS at ILL [72]) are set to open up new possibilities for operando studies of thin-film AEM membranes, while highlighting the evolution of interfacial structures, as has been demonstrated for electrode-electrolyte interfaces [135]. 


\subsection{Water distribution}

Water fulfills a critical role in FCs, where optimal operational conditions require elevated hydration levels inside the membrane itself and moderate amounts of water in other components. Too high water content results in issues such as backdiffusion, increased Ohmic loss, hindered flow of reactant gases, and a reduction in the availability of active sites on the electrocatalyst [137]. In contrast, too low water content enhances AEM degradation, which is already an issue due to the alkaline environment [138]. It is therefore imperative to understand and control water distribution within the device under operational conditions to optimize the technology.

On a microscopic level, small-angle neutron scattering (SANS) provides an additional probe to assess the hydrophobic-hydrophilic phase-separated structure of membrane materials, that can be extended to in situ measurements [24]. Isotopic (H/D) substitution techniques allow decoupling of the scattering contributions from different components, while placing constraints on the models used to analyse the scattering data, such as the empirical potential structure refinement technique [139]. The spatial range analysed typically extends between interatomic $\left(Q \sim 50 \AA^{-1}\right)$ to tens of nanometers ( $Q=0.02 \AA^{-1}$ for NIMROD at ISIS) distances [140], allowing simultaneous measurements of complementary structural information across different length scales of interest.

Neutron radiography/imaging (NI) is used to visualise the system at the macroscopic level and can specifically be applied to view the solvent distribution in a polymer medium in real time. A neutron radiograph is a spatially resolved neutron transmission measurement of an object, where the total transmission $(T)$ is given by the Beer-Lambert law

$$
T=I / I_{0}=\mathrm{e}^{-\sum_{i}(N \sigma t)_{i}}
$$

where $N$ is the number density, $t$ is the sample thickness, and $\sigma$ is the scattering cross section.

The spatial resolution $(L / d)$ is dictated by aperture diameter $(d)$ and the detector-aperture separation distance $(L)$, as well as consideration and evaluation of the distance between sample and detector $\left(z_{d}\right)$, that causes blurring at the edges $\left(\lambda_{\mathrm{g}}=z d / L\right)$. We note that NI requires longer acquisition times than complementary $\mathrm{x}$-ray experiments, and the spatial resolution is, at present, limited to a few $\mu \mathrm{m}$. However, this is expected to improve with next generations of beamline design and detector experiments.

Because of its high penetration (a few $\mathrm{cm}$ ) through samples and their metallic containers combined with its high sensitivity to $\mathrm{H}$-containing materials and processes, NS/NR/NI provide excellent tools to probe water distribution in a matrix of variable composition. By comparing images taken before and after hydration, it is possible to extract, in real time, quantitative thickness data on the hydrated layer and hence information on the mass distribution within the sample. NR and NI can be used to evaluate membrane swelling upon operation. Here, it is necessary to account for possible compression of the membrane on the gas-diffusion layer, which might cause mis-interpretation of the water content, especially at the edges of the sample. NI has recently been implemented to
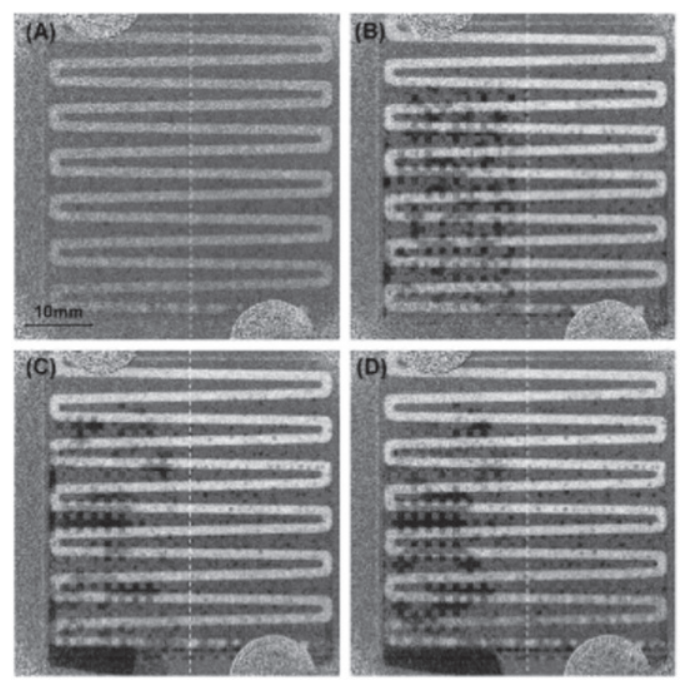

Figure 7. Water formation and transport in a direct methanol fuel cell with hydrophylic (right) and hydrophobic (left) regions after (a)-(d) $0,15,30$, and 60 min respectively, showing darkened areas from water accumulation. Reprinted from [141], Copyright (2011), with permission from Elsevier.

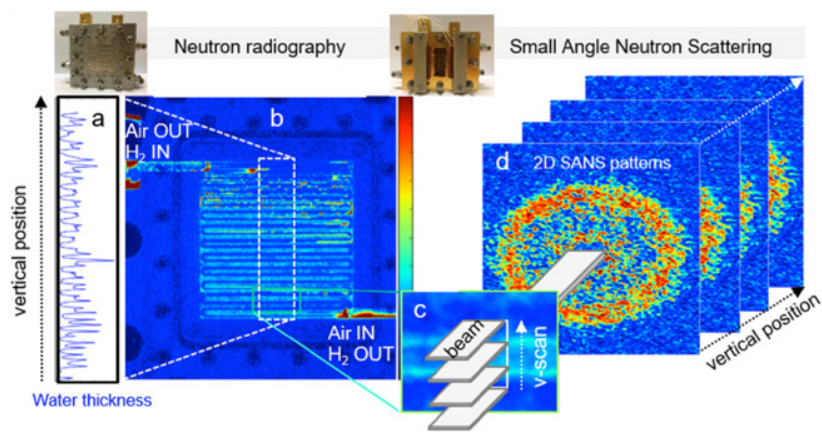

Figure 8. Parallel NI and SANS in fuel cells operated in counter-flow configurations. Reprinted with permission from [24]. Copyright (2019) American Chemical Society.

study through-plane water distribution in FC devices under operational conditions for understanding mass transport and performance (figure 7) [24, 26, 27, 141].

Innovative experiments combining NI and SANS profiles were recently used to analyze the water distribution within a commercial MEA formed with a Gore Nafion membrane [24]. The results showed the development of large in-plane and through-plane gradients, revealing that the water distribution is governed, under operational conditions, by a complex twophase flow along with evaporation/condensation processes (figure 8) [24].

Parallel neutron imaging and operando micro x-ray computed tomography experiments performed on operating AEMFC devices revealed both water accumulation at the anode and dry-out at the cathode side [142]. The observations suggest that operating conditions leading to the highest power density during polarization are not generally those that allow long-term stable operation [142], and the NS results thus serve as a guide for design and optimisation of new catalyst and gas diffusion layers. 
In a joint project between Université Grenoble Alpes and ILL, a new instrument (NeXT-Grenoble) is now available to simultaneously acquire neutron tomography and x-ray absorption imaging data, taking advantage of the high complementarity between these two techniques [143]. Instead of discriminating among the wavelengths of incident and scattered neutrons using a TOF approach, NeXT-Grenoble takes advantage of the wavelength-dependency of their deflection by a prism [72], leading to highly spatially resolved wavelength determination. A similar NeXT instrument is also available at the NIST Center for neutron research in the USA [144].

At ILL D22, a portable SAXS system is now being installed to perform nanoscale structural (SANS/SAXS) studies [145]. Such new directions pave the way for real-time investigations of a wide range of nanomaterials and processes. In one recent example, a combination of x-ray and neutron tomography was used to track Li intercalation and electrode degradation in battery devices [146].

\subsection{Ion hopping and water diffusion}

Optimizing the durability and stability of AEMs requires a deep understanding of the $\mathrm{OH}^{-}$and $\mathrm{H}_{2} \mathrm{O}$ transport, and how these are modulated by the polymer dynamics, especially under realistic operando conditions (as for PEM; figure 9). QENS provides an ideal set of tools to probe and disentangle (because of its intrinsic sensitivity to isotopic composition) microscopic dynamical events that control the physical processes, as well as to determine how the properties evolve under external stimuli in their functional environment.

Incoherent QENS provides a direct measurement of the dynamical structure factor $(S(Q, \omega))$ of all hydrogen $(\mathrm{H})$ atoms in a sample. These dynamics are typically decomposed into vibrational $(V)$, translation $(T)$ and rotational $(R)$ contributions. Assuming these dynamics are uncorrelated with each other, the measured scattering function is a convolution of these terms:

$$
S_{\mathrm{inc}}(Q, \omega)=S^{V} \otimes S^{T} \otimes S^{R}
$$

Assuming that the vibrations are isotropic and harmonic, this expression simplifies to:

$$
S_{\text {inc }}(Q, \omega)=\mathrm{e}^{-\frac{1}{3} Q^{2} u^{2}} S^{T} \otimes S^{R} .
$$

Because they constitute a thermally activated process, a good first approach to disentangle different dynamical contributions is given by the study of fixed window scan (FWS) data, achievable by following the evolution of the scattering signal within a fixed energy transfer range $(\Delta E)$ upon heating or cooling the sample.

The elastic fixed window scan (EFWS; $\Delta E \approx 0$ ) provides an effective means to locate the temperatures at which each contribution to the relaxation dynamics enters or exceeds the time (or energy) window of the spectrometer, giving rise to characteristic changes in slope of the EFWS signal. It is therefore extremely useful for selecting temperature ranges in which useful QENS measurements can be performed. EFWS is also useful to evaluate the temperature dependence of the
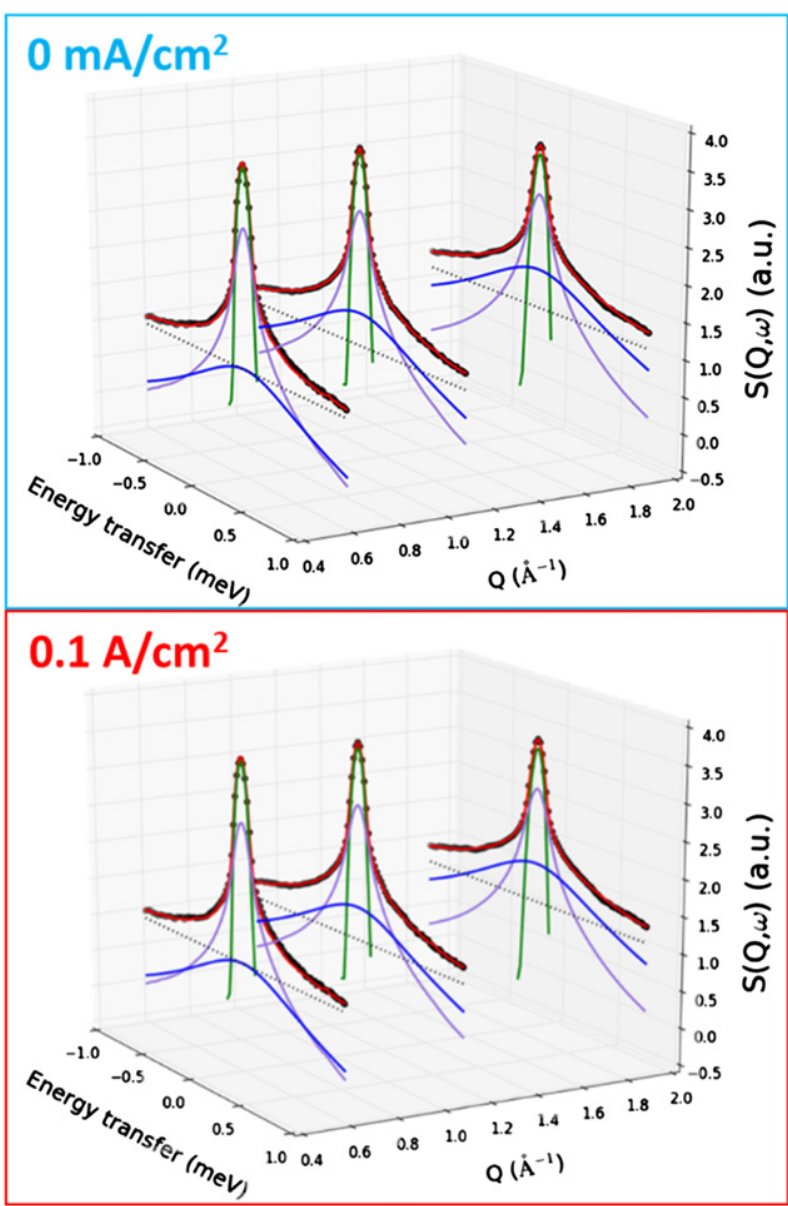

Figure 9. PEMFC QENS spectra (black) and fits (red) consisting of the sums of fitted water diffusion (purple), water rotation/vibration (blue) and elastic contributions (green). Data taken at $80 \mu \mathrm{eV}$ (IN5, ILL) without (top, blue) and with (bottom, red) drawing current. Reprinted with permission from [25]. Copyright (2018) American Chemical Society.

mean-square displacement (msd; $\left\langle u^{2}\right\rangle$; equation (7)) of hydrogen atoms, given by the slope at low $T$.

$$
\frac{I_{\text {in } c_{\text {elastic }}}(Q, T)}{I_{\text {in } c_{\text {elastic }}}\left(Q, T_{\min }\right)}=\exp \left(-\frac{1}{3} Q^{2}\left(\left\langle u^{2}\right\rangle-\left\langle u^{2}\right\rangle_{T_{-} \min }\right)\right) \text {. }
$$

Equally useful is examination of the complementary inelastic fixed window scan (IFWS; obtained at $\Delta E \neq 0$ ). Depending on the neutron spectrometer used, this can be obtained by integrating the QENS signal over energy intervals (with a width generally equivalent to the instrumental energy resolution) centered at different positions of the Lorentzian broadening, as is the case for the BS spectrometers at ISIS IRIS and OSIRIS, or by measuring QENS intensity with a fixed Doppler speed, as used at the high resolution BS spectrometer IN16B at ILL [147]. In the IFWS technique, a temperature scan probes the variation in relaxation time (inducing a change in the inelastic signal; $\tau$ ) which reaches a maximum when the QENS broadening matches $\omega_{\text {off }}$ (i.e., the energy offset) [147]. Recording the IFWS can further discriminate between local ( $Q$-independent) versus diffusive ( $Q$-dependent) motions, as well as the activation energy $\left(E_{\mathrm{A}}\right)$ of each process under examination, as demonstrated by the following 
relations:

$$
I_{\omega_{\text {off }}}^{\mathrm{IFWS}} \propto \frac{\mathrm{B}}{\pi}\left(1-A_{0}(Q)\right) \frac{\tau(T)}{1+\omega_{\mathrm{off}}^{2} \tau(T)^{2}}
$$

and

$$
\tau(T)=\tau_{0} \exp \left(-\frac{E_{\mathrm{A}}}{K T}\right) .
$$

In these equations, $B$ is a constant which accounts for the resolution function, $\tau_{0}$ is the upper limit of the relaxation time, $A_{0}$ is the elastic incoherent structure factor and $\kappa$ is Boltzmann's constant.

From a practical point of view, in complex systems such as hydrated membranes, the scattering function is given by a few terms associated with the polymer $\left(S_{\mathrm{P}}\right)$ and water $\left(S_{\mathrm{W}}\right)$ dynamics, so that the scattering function can be expressed as:

$$
\begin{aligned}
S(Q, \omega)= & \left\{\delta(\omega) \Phi_{\text {immobile }}+\left(1-\Phi_{\text {immobile }}\right)\right. \\
& \left.\times\left[x_{1} S_{\mathrm{P}}(Q, \omega)+\left(1-x_{1}\right) S_{\mathrm{W}}(Q, \omega)\right]\right\} \otimes R(\omega)
\end{aligned}
$$

Here $R(\omega)$ represents the instrumental resolution function, that is determined experimentally using a vanadium $(\mathrm{V})$ standard, or from measurements of the sample at very low temperatures $(\sim 2-10 \mathrm{~K})$.

As expressed in equation (10), the experimental scattering function contains an implicit 'resolution effect' incorporated within $R(\omega)$, which translates into specific dynamics being 'visible or not' within the time-scale accessible by a specific instrument and its energy- or timescale resolution capabilities (figures 10(a) and (b)). Practically, this means that slower dynamics that lie outside the resolution window are incorporated into the $\delta(\omega)$ function, while faster dynamics may vanish into the background. To probe the full range of the dynamics, it is necessary to carry out complementary studies of the same materials at different instruments, under comparable experimental conditions. To ensure the reliability of the analysis, the same analytical correlation function must be used to describe the dynamics across the extended range of timescales, where the weight of the various components is evaluated and expressed according to the dynamic window of each experiment. Such experiments carried out across multiple probe timescales under complementary conditions then provide additional constraints on chosen models for the membrane and ionic conduction dynamics, thus facilitating the interpretation of the datasets and their implementation for design and optimisation of FC membranes and devices.

It is also advantageous to apply the same cross-correlated analysis to study the scattering profile in the time domain, that is obtained by Fourier transforming $S(Q, \omega)$ (figure 10(c)). In this case, different datasets are readily normalised according to the relevant resolution function, and the full range of data can be treated using a single analytical function.

In this scenario, equation (10) becomes:

$$
\begin{aligned}
I(Q, t)= & x_{1} I_{\mathrm{P}}(Q, t)+\left(1-x_{1}\right)\left[N_{\text {slow }} I_{W_{\text {slow }}}(Q, t)\right. \\
& \left.+N_{\text {fast }} I_{W_{\text {fast }}}(Q, t)\right] \cdot R(t)
\end{aligned}
$$
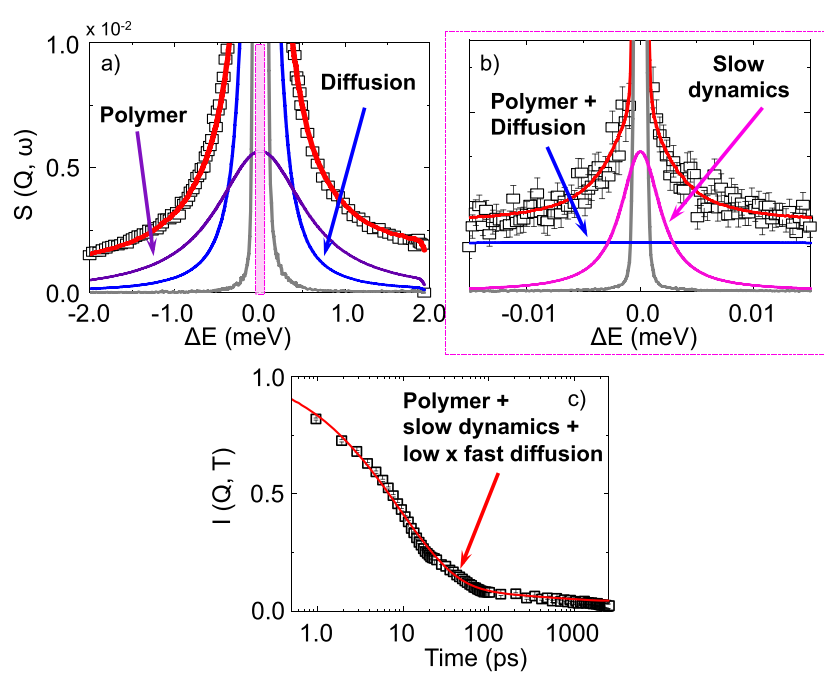

Figure 10. Comparison between scattering profiles acquired at two instrumental resolutions (namely 70 and $0.75 \mu \mathrm{eV}$; IN6-SHARP and IN16B) showing the 'resolution effect' (a) and (b). Combined data Fourier transformed into the time domain to reveal different relaxation dynamics operating sequentially across different timescale ranges (c).

where

$$
I_{\mathrm{W}_{\text {fast }}}(Q, t)=I_{\text {localised }}(Q, t) \cdot I_{\text {longrange }}(Q, t)
$$

which accounts for the coupling between (nano-)localized and long-range diffusion motions and relaxations.

Such an approach has been applied extensively to studies of Nafion membranes, related model polymer materials, and water transport additives of interest [13-18, 43]. It allows two types of protons to be distinguished: slow and fast moving. The former population is hydration-independent and consists of three protons (i.e. $\mathrm{H}_{3} \mathrm{O}^{+}$) involved in the dynamics, and is present also in the almost dry sample. The second emerges upon more extensive membrane hydration, and relates to hydration water dynamics, a process that is intrinsically subdiffusive within the nanoscale hydrophilic channels of an ionic material. At pico- to nanosecond time scales, the diffusion of water molecules can be modelled as fast intradroplet localized motions (i.e., quantified by a local diffusion coefficient $D_{\text {loc }}$ ) and slower inter-droplet long-range diffusion (quantified by $D_{\text {nano }}$ ) $[15-17,23]$. Similar dynamics are also found in self-assembled perfluorinated surfactants, where the nature of the phase plays a role in the level of confinement [15-17, 23]. These results combined with extensive structural studies as well as benchmarking with (PFG-) NMR data (providing information on the self-diffusion coefficient at microscale, $D_{\mathrm{s}}$ ) and MD simulations, allow the ionic conductivity results to be correlated with the material chemistry. Key features are that: (i) water cannot establish hydrogen bonds with the Nafion skeleton due to the highly hydrophobic backbone, (ii) the characteristics of nanoscale phase separation drive the low hydration behaviour by imposing strongly sub-diffusive motions, (iii) structural rearrangements upon swelling impact the global balance between interactions, topology and connectivity, and (iv) fast vs slow proton mobility relate to 

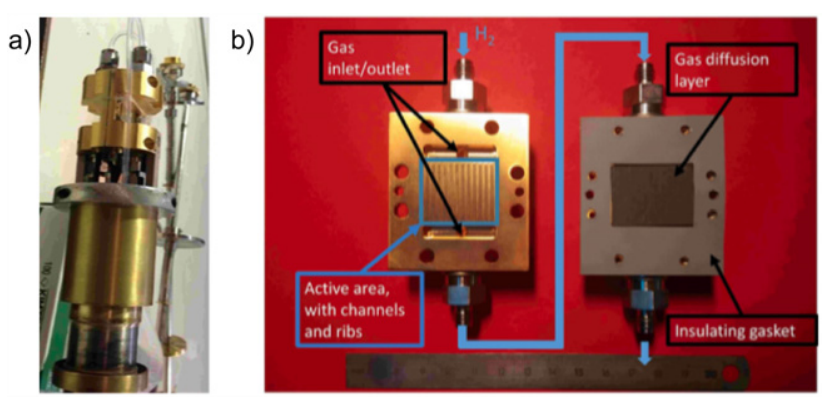

Figure 11. Cell design for PEMFC QENS studies under operational condition. (a) Sample stick; (b) fuel cell and sketch of the operation principle. Reprinted with permission from [25]. Copyright (2018) American Chemical Society.

strongly-interacting and bulk-like dynamics which are intimately coupled and determine the molecular level mechanism of ion conduction [23].

A similar approach has been extended to describe water, ion, and polymer dynamics within commercial AEM membranes. One of the principal difficulties in approaching the study of AEMs is related to the backbone chemistry. Because it is an H-containing polymer material it is not 'invisible' to QENS, as in the case for Nafion. To bypass this issue, selective deuteration of the polymer matrix is often necessary to complete the study. For studies of commercial materials, an alternative approach would include hydrating the membrane in $\mathrm{D}_{2} \mathrm{O}$ or use of a null scattering $\mathrm{D}_{2} \mathrm{O} / \mathrm{H}_{2} \mathrm{O}$ mixture. In the latter case, it is then possible to disentangle polymer segmental relaxation from water dynamics and address their dynamics separately.

Performing neutron studies in operational conditions (especially in the case of fuel cells) necessitates a delicate and complex optimization of cell dimensions and geometry to maximize transmission and scattering while operating in representative conditions of flow, relative humidities, temperature, current density, etc. Pioneering studies at ILL have established the applicability of QENS to monitor in situ water dynamics in PEMFCs (figure 11) [25].

Carrying out these experiments required an extensive programme of sample environment design to (i) hydrate uniformily the membrane over the investigated footprint (i.e. PEMFC is heterogeneously hydrated due to mass transport losses and heat production [21]), and (ii) ensure that application of the current did not change either the hydration state or membrane homogeneity. Interestingly, the comparison between in situ and ex situ results indicated no difference in the overall performance, suggesting that ex situ data might be sufficient to be used to provide realistic inputs for modelling and evaluating FC performance under operational conditions [25].

\subsection{Simultaneous studies}

It is clear that complex systems such as membranes and/or hierarchical structures need more than one single technique to achieve a detailed understanding of the interplay between microscopic physical processes and structure at the macroto meso-scale. Furthermore, as the structural complexity increases, so do the challenges to guide the transition from

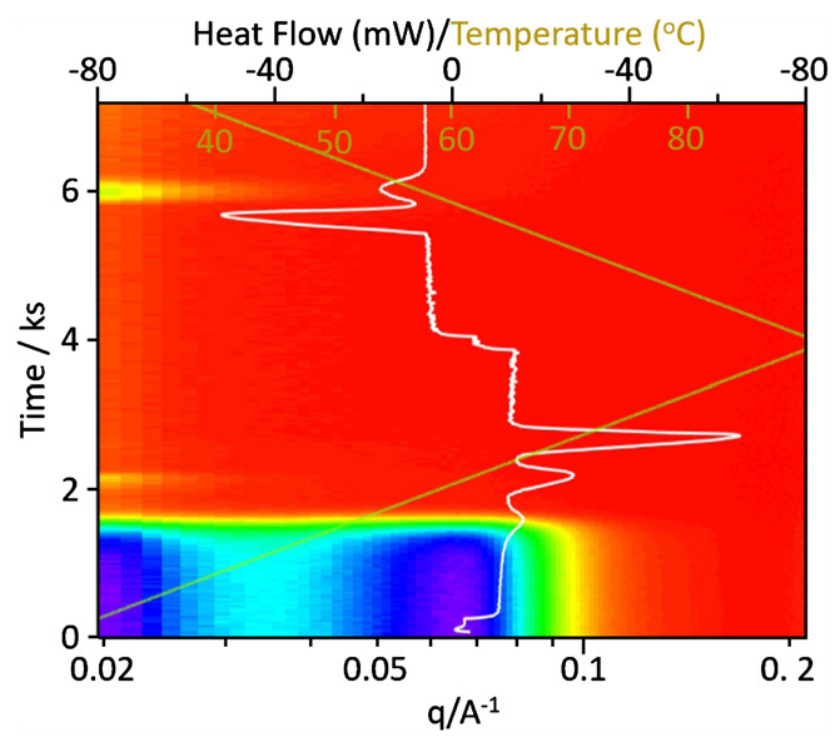

Figure 12. Simultaneous SANS/DSC measurements during 35-90-35 ${ }^{\circ} \mathrm{C}$ temperature sweep for $\mathrm{C}_{30} \mathrm{H}_{62} / \mathrm{C}_{36} \mathrm{D}_{72}$ mixture. Reproduced from [150]. ๑ IOP Publishing Ltd. All rights reserved.

theoretical properties to practical applications. Furthermore it is challenging to replicate the same experimental conditions, especially when dealing with commercially available samples. It is therefore crucial to implement and develop instruments and capabilities to perform simultaneous studies to test the relative importance of essential physical and operational parameters.

Recent examples of work implementing these principles some of which have been cited above include: simultaneous SAXS/WAXS - UV-Vis measurements [148], SANSdynamic light scattering (DLS) [149], SANS-differential scanning calorimetry (DSC; figure 12) [150] and SANSnuclear magnetic resonance (NMR) [151].

This last combination to be installed on the new SHARP spectrometer (ILL) will include an NMR spectrometer to allow probing excitations and relaxation events from the pico- (neutrons) to milli-second (NMR) ranges. This combination will enable characterization of the diffusion processes of water molecules confined and partly mobile within a polymer membrane. A similar concept applies to the newly designed sample holders and environments suitable for combined multiple experiments at IRIS (ISIS) [152, 153].

New sample environments enabled by instruments with enhanced access space will allow increased use of combined NS with other techniques ranging from optical spectroscopy to $\mathrm{x}$-ray diffraction and imaging, reactant/gas flow and electrical inputs and measurement that are all relevant to $\mathrm{FC}$ and other energy materials and device measurements. Raman scattering that provides complementary vibrational information to INS and QENS studies is enabled using a 'Raman center-stick' arrangement inserted into the $100 \mathrm{~mm}$-bore cryostat developed at ISIS and implemented at TOSCA and IRIS $[152,154,155]$ and would be suitable to complement structural studies at high count-rate neutron diffractometers such as GEM [156] and POLARIS [157]). Such a sample holder and 
investigation geometry would perfectly apply to monitor potential degradation of AEM materials in harsh alkaline environments, while simultaneously studying the polymer/water dynamics. Other opportunities afforded by new sample holders developed at ISIS allow performing simultaneous QENS and DSC measurements [153]. QENS and DSC are complementary techniques applied to map phase transition temperatures and identify sample states. EFWS data are readily correlated with results of a DSC scan. At present, sample holders are only available for $0.5 \mathrm{~mm}$ and $1 \mathrm{~mm}$ annular can sample holders sealed with Indium wire. This configuration limits studies to non-viscous liquids (e.g. deuterated materials or hydrogenated components in deuterated solution) in a temperature range not exceeding $373 \mathrm{~K}$. Efforts are now under way to extend the capability to powder/film samples as well to reduce the can thickness, to MAE these suitable for work with hydrogenated solutions [158]. Both of these new exciting opportunities will open up possibilities such as monitoring not only polymer glass transitions $\left(T_{\mathrm{g}}\right)$ but also the nature of freezable vs unfreezable water, in bulk vs nano-confined bulk states as well as contained within FC membranes.

\section{Conclusions}

Functional membranes are hierarchical structures in which defined macroscopic properties and specific functionalities are the results of a delicate balance between fundamental chemistry and physical processes of the assemblies as well as their processing conditions. Because of this intrinsic complexity, despite improvements, predicting and optimizing overall performance is still poorly understood, as it requires a detailed understanding of the interplay between microscopic physical processes and structure at the macro- to meso-scale. Furthermore, as the structural complexity increases, so do the challenges to guide the transition from theoretical properties to practical applications. It is, therefore, crucial to develop the ability to deconvolve the relationships between intermolecular interactions and relaxation processes over a wide range of time and distance scales.

In the specific case of fuel cell operation and design, one of the most promising ways to improve performance is via water management optimization. The main challenge is, therefore, identifying materials that selectively transport or reversibly absorb molecules, where a precise design and control over inner architecture is necessary to enhance performance and durability, while avoiding unwanted phenomena such as compaction and/or undue swelling. Achieving this requires a methodology that: (i) provides information on the chemical profiling, transport and nanoconfinement dynamics across many length and time scales, (ii) can be used to guide the design form bulk material to up-scaling production, and (iii) can be extended from ex/in situ laboratory experiments to studies under realistic operational conditions to determine how properties evolve under external stimuli in their functional environment.

NS techniques provide an ideal set of tools to achieve these goals. They offer critical complementarity to computational modeling studies, where experimental parameters are used to feedback into model inputs, providing an effective methodology to understand the formation, stability, and properties of materials, as well as guiding advanced designs, especially as advanced neutron instrumentation is being developed and implemented at high-brilliance sources worldwide.

\section{Acknowledgments}

FF, GG, PFM and AJC have been supported by the EU Graphene Flagship under Horizon 2020 Research and Innovation program Grant Agreement No. 881603-GrapheneCore3, and FF and PFM by the EPSRC Materials Research Hub for Energy Conversion, Capture, and Storage (M-RHEX) EP/R023581/1. AJC would like to thank the Society of Chemical Industry and the Ramsay Memorial Fellowship Trust for funding. The SHARP spectrometer has been designed and built in the framework of the cooperation agreement for the development and construction of neutron instrumentation between the Swedish Research Council and the French Research agencies CEA and CNRS.

\section{Data availability statement}

No new data were created or analysed in this study.

\section{ORCID iDs}

Fabrizia Foglia (D) https://orcid.org/0000-0002-2847-3489 Adam J Clancy (D) https://orcid.org/0000-0002-1791-8999

\section{References}

[1] Tan R et al 2020 Nat. Mater. 19195

[2] Werber J R, Osuji C O and Elimelech M 2016 Nat. Rev. Mater. 116018

[3] Park M, Ryu J, Wang W and Cho J 2016 Nat. Rev. Mater. 2 16080

[4] Joshi R K, Carbone P, Wang F C, Kravets V G, Su Y, Grigorieva I V, Wu H A, Geim A K and Nair R R 2014 Science $\mathbf{3 4 3} 752$

[5] Trigg E B, Gaines T W, Maréchal M, Moed D E, Rannou P, Wagener K B, Stevens M J and Winey K I 2018 Nat. Mater. 17725

[6] Park C H et al 2016 Nature 532480

[7] Gin D L and Noble R D 2011 Science 332674

[8] Dekel D R 2018 J. Power Sources 375158

[9] Huang G, Mandal M, Peng X, Yang-Neyerlin A C, Pivovar B S, Mustain W E and Kohl P A 2019 J. Electrochem. Soc. 166 F637

[10] Shen G et al 2020 Nat. Commun. 111191

[11] Gebel G 2000 Polymer 415829

[12] Kusoglu A and Weber A Z 2017 Chem. Rev. 117987

[13] Volino F, Pineri M, Dianoux A J and De Geyer A $1982 \mathrm{~J}$. Polym. Sci. Polym. Phys. Ed. 20481

[14] Paciaroni A, Casciola M, Cornicchi E, Marconi M, Onori G, Pica M and Narducci R 2006 J. Phys. Chem. B 11013769

[15] Perrin J-C, Lyonnard S and Volino F 2007 J. Phys. Chem. C 1113393

[16] Lyonnard S, Berrod Q, Brüning B-A, Gebel G, Guillermo A, Ftouni H, Ollivier J and Frick B 2010 Eur. Phys. J. Spec. Top. 189205

[17] Berrod Q, Hanot S, Guillermo A, Mossa S and Lyonnard S 2017 Sci. Rep. 78326 
[18] Hanot S, Lyonnard S and Mossa S 2016 Nanoscale 83314

[19] Melchior J-P, Lohstroh W, Zamponi M and Jalarvo N H 2019 J. Membr. Sci. $\mathbf{5 8 6} 240$

[20] Melchior J-P and Jalarvo N H 2019 J. Phys. Chem. C 123 14195

[21] Morin A, Gebel G, Porcar L, Peng Z, Martinez N, Guillermo A and Lyonnard S 2017 J. Electrochem. Soc. 164 F9

[22] Gebel G, Diat O, Escribano S and Mosdale R 2008 J. Power Sources 179132

[23] Lyonnard S and Gebel G 2012 Eur. Phys. J. Spec. Top. 213195

[24] Martinez N et al 2019 ACS Appl. Energy Mater. 28425

[25] Martinez N et al 2018 J. Phys. Chem. C 1221103

[26] Iranzo A, Salva A, Boillat P, Biesdorf J, Tapia E and Rosa F 2017 Int. J. Hydrog. Energy 4213839

[27] Hussey D S et al 2012 J. Appl. Phys. 112104906

[28] Lin X, Varcoe J R, Poynton S D, Liang X, Ong A L, Ran J, Li Y and Xu T 2013 J. Mater. Chem. A 17262

[29] Pandey T P et al 2016 J. Electrochem. Soc. 163 H513

[30] Berrod Q, Lyonnard S, Guillermo A, Ollivier J, Frick B, Manseri A, Améduri B and Gébel G 2015 Macromolecules 486166

[31] Veh P, Britton B, Holdcroft S, Zengerle R, Vierrath S and Breitwieser M 2020 RSC Adv. 108645

[32] Mustain W E, Chatenet M, Page M and Kim Y S 2020 Energy Environ. Sci. 132805

[33] Huang N, Wang P and Jiang D 2016 Nat. Rev. Mater. 116068

[34] Wu D, Xu T, Wu L and Wu Y 2009 J. Power Sources 186 286

[35] Hasani-Sadrabadi M M, Dashtimoghadam E, Majedi F S, Kabiri K, Mokarram N, Solati-Hashjin M and Moaddel H 2010 Chem. Commun. 466500

[36] Yuqian S, Yexin D, Huayuan H, Jieshu Q and Xuan Z 2019 J. Mater. Chem. A 719820

[37] Kwangjin O, Osung K, Byungrak S, Dong H L and Sangaraju S 2019 J. Membr. Sci. $\mathbf{5 8 3} 103$

[38] D'Epifanio A et al 2010 Chem. Mater. 22813

[39] Chang C-M, Li H-Y, Lai J-Y and Liu Y-L 2013 RSC Adv. 3 12895

[40] Steffy N J, Parthiban V and Sahu A K 2018 J. Membr. Sci. 563 65

[41] Chen L et al 2017 Nature 550380

[42] Abraham J et al 2017 Nat. Nanotechnol. 12546

[43] Foglia F et al 2020 Sci. Adv. 6 eabb6011

[44] Patel H A, Mansor N, Gadipelli S, Brett D J L and Guo Z 2016 ACS Appl. Mater. Interfaces 830687

[45] Mukhopadhyay S, Das A, Jana T and Das S K 2020 ACS Appl. Energy Mater. 37964

[46] Foglia F, Karan S, Nania M, Jiang Z, Porter A E, Barker R, Livingston A G and Cabral J T 2017 Adv. Funct. Mater. 27 1701738

[47] Kawakami T, Nakada M, Shimura H, Okada K and Kimura M 2018 Polym. J. 50327

[48] Arbe A, Alvarez F and Colmenero J 2020 Polymers 123067

[49] Paddison S J and Paul R 2002 Phys. Chem. Chem. Phys. 41158

[50] Wang C and Paddison S J 2013 J. Phys. Chem. A 117650

[51] Spohr E 2004 Mol. Simul. 30107

[52] Tuckerman M E, Marx D and Parrinello M 2002 Nature 417 925

[53] Vilčiauskas L, Tuckerman M E, Bester G, Paddison S J and Kreuer K-D 2012 Nat. Chem. 4461

[54] Ghelichi M, Melchy P-É A and Eikerling M H 2014 J. Phys. Chem. B 11811375

[55] Liu H, Chen Y, Hy S, An K, Venkatachalam S, Qian D, Zhang M and Meng Y S 2016 Adv. Energy Mater. 61502143

[56] Siegwart M, Manzi-Orezzoli V, Valsecchi J, Harti R P, Kagias M, Strobl M, Grünzweig C, Schmidt T J and Boillat P 2020 J. Electrochem. Soc. 167064509

[57] Hussey D S, Jacobson D L, Arif M, Coakley K J and Vecchia D F 2010 J. Fuel Cell Sci. Technol. 7021024
[58] Skold K and Price D L 1986 Neutron Scattering (New York: Academic)

[59] Thomason J 2018 https://isis.stfc.ac.uk/Pages/ISIS-II\%20 Roadmap.pdf

[60] https://ill.eu/users/instruments/modernisation-programmes/ endurance/

[61] Bewley R I, Taylor J W and Bennington. S M 2011 Nucl. Instrum. Methods Phys. Res. A 637128

[62] Arbe A et al 2020 Phys. Rev. Res. 2022015

[63] Garlatti E et al 2020 Nat. Commun. 111751

[64] Košata J et al 2017 Physica B 551476

[65] Russina M and Mezei F 2010 J. Phys.: Conf. Ser. 251012079

[66] Perrichon A, Fernandez-Alonso F, Wolff M, Karlsson M and Demmel F 2019 Nucl. Instrum. Methods Phys. Res. A 947 162740

[67] Perrichon A, Fernandez-Alonso F, Wolff M, Karlsson M and Demmel F 2020 J. Synchrotron Invest. 14 S169

[68] Webster J, Holt S and Dalgliesh R 2006 Physica B 385-386 1164

[69] Dalgliesh R M, van Well A A, Boag S, Charlton T R, Frost C D, de Haan V O, Parnell S and Plomp J 2007 Physica B 397 176

[70] Plomp J, de Haan V O, Dalgliesh R M, Langridge S and van Well A A 2007 Thin Solid Films 5155732

[71] Charlton T R, Coleman R L S, Dalgliesh R M, Kinane C J, Neylon C, Langridge S, Plomp J, Webb N G J and Webster J R P 2011 Neutron News 2215

[72] Cubitt R, Segura Ruiz J and Jark W 2018 J. Appl. Crystallogr. 51257

[73] Zanotti J-M et al 2012 Eur. Phys. J. Spec. Top. 213129

[74] Berrod Q, Lagrené K, Ollivier J and Zanotti J-M 2018 Inelastic and quasi-elastic neutron scattering. Application to softmatter EPJ Web Conf. 18805001

[75] Ollivier J and Zanotti J-M 2010 Ecole thématique J. Physique 10379

[76] Berrod Q et al 2016 Nanoscale 87845

[77] Ferdeghini F, Berrod Q, Zanotti J-M, Judeinstein P, Sakai V G, Czakkel O, Fouquet P and Constantin D 2017 Nanoscale 91901

[78] Appel M, Frick B and Magerl A 2018 Sci. Rep. 813580

[79] https://europeanspallationsource.se/about

[80] https://neutrons.ornl.gov/sites/default/files/Proton\%20Power $\% 20$ Upgrade\%20Science\%20Case.pdf

[81] https://neutrons.ornl.gov/sts/documents

[82] Anderson I S, Andreani C, Carpenter J M, Festa G, Gorini G, Loong C-K and Senesi R 2016 Phys. Rep. 6541

[83] Mirfayzi S R et al 2020 Appl. Phys. Lett. 116174102

[84] Carpenter J M 2019 Nat. Rev. Phys. 1177

[85] Qinghao L et al 2020 J. Chem. Phys. 152140901

[86] Pollet B G, Kocha S S and Staffell I 2019 Curr. Opin. Electrochem. 1690

[87] Xie L and Kirk D W 2020 J. Electrochem. Soc. 167064519

[88] Hibbs M R 2013 J. Polym. Sci. B 511736

[89] Varcoe J R et al 2014 Energy Environ. Sci. 73135

[90] Hickner M A, Herring A M and Coughlin E B 2013 J. Polym. Sci. B 511727

[91] Springer T E, Zawodzinski T A and Gottesfeld S $1919 \mathrm{~J}$. Electrochem. Soc. 1382334

[92] Varcoe J R and Slade R C T 2005 Fuel Cells 5187

[93] Marx D, Chandra A and Tuckerman M E 2010 Chem. Rev. 110 2174

[94] Tuckerman M E, Marx D and Parrinello M 2002 Nature 417 925

[95] Dubey V, Maiti A and Daschakraborty S 2020 Chem. Phys. Lett. 755137802

[96] Chen C, Tse Y-L S, Lindberg G E, Knight C and Voth G A 2016 J. Am. Chem. Soc. 138991

[97] Dong D, Zhang W, van Duin A C T and Bedrov D $2018 J$. Phys. Chem. Lett. 9825 
[98] Zhang W, Dong D, Bedrov D and van Duin A C T 2019 J. Mater. Chem. A 75442

[99] Zhang F, Zhang H and Qu C 2011 J. Mater. Chem. 2112744

[100] Mohanty A D, Lee Y-B, Zhu L, Hickner M A and Bae C 2014 Macromolecules 471973

[101] Yan J and Hickner M A 2010 Macromolecules 432349

[102] Wu X et al 2014 J. Mater. Chem. A 212222

[103] Lin X, Liang X, Poynton S D, Varcoe J R, Ong A L, Ran J, Li Y, Li Q and Xu T 2013 J. Membr. Sci. 443193

[104] Li N, Leng Y, Hickner M A and Wang C-Y 2013 J. Am. Chem. Soc. 13510124

[105] Lin X, Wu L, Liu Y, Ong A L, Poynton S D, Varcoe J R and Xu T 2012 J. Power Sources 217373

[106] Ran J, Wu L, Wei B, Chen Y and Xu T 2014 Sci. Rep. 46486

[107] Gottesfeld S, Dekel D R, Page M, Bae C, Yan Y, Zelenay P and Kim Y S 2018 J. Power Sources 375 170

[108] Subianto S, Pica M, Casciola M, Cojocaru P, Merlo L, Hards G and Jones D J 2013 J. Power Sources 233216

[109] You W, Padgett E, MacMillan S N, Muller D A and Coates G W 2019 Proc. Natl Acad. Sci. USA 1169729

[110] Zardalidis G, Pipertzis A, Mountrichas G, Pispas S, Mezger M and Floudas G 2016 Macromolecules 492679

[111] Lu J, Barnett A and Molinero V 2019 J. Phys. Chem. C 123 8117

[112] Zhu L, Pan J, Wang Y, Han J, Zhuang L and Hickner M A 2016 Macromolecules 49815

[113] Tanaka M, Fukasawa K, Nishino E, Yamaguchi S, Yamada K, Tanaka H, Bae B, Miyatake K and Watanabe M $2011 \mathrm{~J}$. Am. Chem. Soc. 13310646

[114] Lee W H et al 2017 ACS Macro Lett. 6566

[115] Wang L, Peng X, Mustain W E and Varcoe J R 2019 Energy Environ. Sci. 121575

[116] Arges C G, Wang L, Parrondo J and Ramani V 2013 J. Electrochem. Soc. 160 F1258

[117] Becerra-Arciniegas R-A, Narducci R, Ercolani G, Antonaroli S, Sgreccia E, Pasquini L, Knauth P and Di Vona M L 2019 Polymer 185121931

[118] Wang L, Bellini M, Miller H A and Varcoe J R 2018 J. Mater. Chem. A 615404

[119] Murthi V S, Dura J A, Satija S and Majkrzak C F 2008 ECS Trans. 161471

[120] Kawamoto T, Aoki M, Kimura T, Mizusawa T, Yamada N L, Miyake J, Miyatake K and Inukai J 2019 Japan. J. Appl. Phys. 58 SIID01

[121] Ueda S, Koizumi S, Ohira A, Kuroda S and Frielinghaus H 2018 Physica B 551309

[122] Kalisvaart W P, Fritzsche H and Mérida W 2015 Langmuir 31 5416

[123] Dura J A, Murthi V S, Hartman M, Satija S K and Majkrzak C F 2009 Macromolecules 424769

[124] DeCaluwe S C, Kienzle P A, Bhargava P, Baker A M and Dura J A 2014 Soft Matter 105763

[125] Wood D L III, Chlistunoff J, Majewski J and Borup R L 2009 J. Am. Chem. Soc. 1311809

[126] Kimura T, Kawamoto T, Aoki M, Mizusawa T, Yamada N L, Miyatake K and Inukai J 2020 Langmuir 364955

[127] Kimura T, Matsumoto A, Inukai J and Miyatake K 2020 ACS Appl. Energy Mater. 3469
[128] Pont S, Foglia F, Higgins A M, Durrant J R and Cabral J T 2018 Adv. Funct. Mater. 281802520

[129] Seidlhofer B-K, Jerliu B, Trapp M, Hüger E, Risse S, Cubitt R, Schmidt H, Steitz R and Ballauff M 2016 ACS Nano 10 7458

[130] Ruderer M A and Müller-Buschbaum P 2011 Soft Matter 7 5482

[131] Hafner A, Gutfreund P and Toperverg B P 2D reflectometry for the investigation of polymer interfaces: off-specular neutron scattering (submitted).

[132] Hynes E L, Gutfreund P, Parnell A J and Higgins A M 2020 Soft Matter 163727

[133] Chandan A, Hattenberger M, El-Kharouf A, Du S, Dhir A, Self V, Pollet B G, Ingram A and Bujalski W 2013 J. Power Sources 231264

[134] Lee K H, Lee S Y, Shin D W, Wang C, Ahn S-H, Lee K-J, Guiver M D and Lee Y M 2014 Polymer 55 1317

[135] Bose S, Kuila T, Nguyen T X H, Kim N H, Lau K-t and Lee J H 2011 Prog. Polym. Sci. 36813

[136] Yamada N L et al 2020 J. Appl. Crystallogr. 531462

[137] Vincent I, Lee E-C and Kim H-M 2020 RSC Adv. 1016844

[138] Diesendruck C E and Dekel D R 2018 Curr. Opin. Electrochem. 9173

[139] Soper A 1996 Chem. Phys. 202295

[140] Bowron D T et al 2010 Rev. Sci. Instrum. 81033905

[141] Tötzke C et al 2011 J. Power Sources 1964631

[142] Peng X et al 2020 Nat. Commun. 113561

[143] Tengattini A, Lenoir N, Andò E, Giroud B, Atkins D, Beaucour J and Viggiani G 2020 Nucl. Instrum. Methods Phys. Res. A 968163939

[144] LaManna J M, Hussey D S, Baltic E and Jacobson D L 2017 Rev. Sci. Instrum. 88113702

[145] Metwalli E et al 2020 J. Appl. Crystallogr. 53722

[146] Ziesche R F 2020 Nat. Commun. 11777

[147] Frick B, Combet J and van Eijck L 2012 Nucl. Instrum. Methods Phys. Res. A 6697

[148] Chen X, Schröder J, Hauschild S, Rosenfeldt S, Dulle M and Förster S 2015 Langmuir 3111678

[149] Kohlbrecher J, Bollhalder A, Vavrin R and Meier G 2007 Rev. Sci. Instrum. 78125101

[150] Pullen S A, Booth N, Olsen S R, Day B, Franceschini F, Mannicke D and Gilbert E P 2014 Meas. Sci. Technol. 25 055606

[151] de Oliveira-Silva R et al 2019 J. Neutron Res. 21155

[152] Adams M A, Parker S F, Fernandez-Alonso F, Cutler D J, Hodges C and King A 2009 Appl. Spectrosc. 63727

[153] Fornalski D, García Sakai V, Postorino S, Silverwood I, Goodway C, Bones J, Kirichek O and Fernandez-Alonso F 2019 Low Temp. Phys. 45289

[154] Parker S F et al 1998 Physica B 241-243 154

[155] Carlile C J and Adams M A 1992 Physica B 182431

[156] Day P et al 2004 Neutron News 1519

[157] Hull S, Smith R I, David W I F, Hannon A C, Mayers J and Cywinski R 1992 Physica B 180-181 1000

[158] Ponsonby J 2019 In situ calorimetry with quasi-elastic neutron spectroscopy: realising a complementary dynamic and thermodynamic sample description ISIS Internal Report 